\title{
Влияние структуры собственности на эффективность деятельности на примере российских и бразильских компаний
}

\author{
Масленникова М.А. ${ }^{5}$, Степанова А.Н. ${ }^{6}$
}

В основу статьи положено эмпирическое исследование, посвященное изучению влияния структуры собственности на эффективность деятельности компании в контексте интегрированного подхода финансовой архитектуры. Объектом исследования выступили крупнейшие бразильские и российские публичные компании, котирующцеся на бразильской и российской фондовых биржах на конец 2008 года. В исследовании использована уникальная база данных, собранная авторами на базе Лаборатории корпоративных финансов ГУ ВШЭ.

Авторы вносят вклад в литературу, во-первых, путем использования комплексной концеепции при моделировании эффективности деятельности компании. Во-вторых, $в$ работе представлено изучение моделей эффективности кризисного периода с целью выявления изменений в механизме формирования корпоративной эффективности в результате кризиса. Наконеи, авторами проведен межстрановой анализ моделей эфрективности в двух из четырех стран группь БРИК, объединяющей наиболее быстроразвиваюшиеся страньл.

\section{JEL: G32}

Ключевые слова: структура собственности, структура капитала, финансовая архитектура, корпоративная эффективность, эффективность деятельности компании, корпоративное управление

\section{Введение}

В условиях возрастающей конкуренции на мировом рынке капитала максимизация корпоративной эффективности представляется жизненно важной задачей для любой компании. Таким образом, выявление детерминантов эффективности деятельности компаний представляет собой актуальную исследовательскую задачу, особенно принимая во внимание кризисный 2008 год, выбранный для исследования. Большое количество работ, посвященных данной проблематике, также свидетельствует о наличие активного интереса к этой проблеме в мировом научном сообществе.

Для моделирования эффективности деятельности компании авторами применен интегрированный подход с использованием концепции финансовой архитектуры (financial architecture), предложенный Стюартом Майерсом [Myers, 1999] и позволяющий рассмотреть характер воздействия системы структурных характеристик компании на эффективность ее деятельности. Эмпирическое применение данного подхода на растущих рынках капитала предложено в работе Ивашковской и Степановой [Ivashkovskaya, Stepanova, 2010], где концепция финансовой архитектуры была использована для моделирования корпоративной эффективности европейских компаний.

В этой статье авторы выстроили модели эффективности российских и бразильских компаний с целью выявления различий в механизмах формирования стоимости компании за счет таких факторов, как структура капитала, структура собственности, отдельных характеристик корпоративного управления, чье взаимодействие и взаимовлияние учитывает концепция финансовой архитектуры. Новизна работы обусловлена также тестированием моделей на данных кризисного периода, что, безусловно, интересно как с точки зрения

\footnotetext{
${ }^{5}$ Бакалавр факультета экономики (2010), ГУ ВШЭ.

${ }^{6}$ Канд. эконом. наук, младший научный сотрудник Лаборатории корпоративных финансов ГУ ВШЭ.
} 
науки, так и с точки зрения практики. Стейкхолдеры компаний не могут не задаваться вопросом, какие характеристики и какая архитектура компании являются наиболее жизнеспособными в условиях глобального финансового кризиса. Поэтому исследование нацелено также на ответ на следующие вопросы: какие решения позволят компании не только выжить в тяжелых условиях сжатого мирового рынка капитала, но и привлечь немногих инвесторов, сохранивших присутствие на рынке; как оптимизировать корпоративную архитектуру таким образом, чтобы в посткризисных условиях компания могла бы рассчитывать на доверие инвесторов и низкие затраты на капитал.

Данная статья структурирована следующим образом: сначала представлен краткий обзор имеющихся теоретических и эмпирических работ на развитых рынках капитала, а также в России и Бразилии. Далее приводится описание методологической базы исследования (сконструированная выборка, выдвинутые гипотезы, спецификация модели); в статье также представлены полученные результаты эконометрического анализа, а в заключении - выводы проведенного эмпирического исследования и их возможная интерпретация.

\section{Обзор литературы}

Теоретическую основу исследования составили работы зарубежных и российских авторов по вопросам исследования воздействия структуры собственности и других компонентов финансовой архитектуры на корпоративную эффективность. Проанализированные работы были классифицированы на две группы: исследования на развитых рынках капитала и на развивающихся, а именно на данных России и Бразилии.

Накопленные теоретические знания в области влияния структуры собственности на эффективность деятельности компаний позволяют рассматривать данный вопрос в разрезе таких аспектов, как концентрация собственности, идентификация типа собственника, характер зависимости между структурой собственности и эффективностью деятельности компаний, проблема эндогенности структуры собственности и обратной причинноследственной связи между структурой собственности и эффективностью деятельности компаний.

Так, некоторые исследователи, рассматривавшие развитые рынки капитала, не обнаружили значительной взаимосвязи между концентрацией собственности и эффективностью деятельности компании [Demsetz and Villalonga, 2001], другие авторы отмечали серьезное влияние [Monsen, Chiu and Cooley, 1968; McEachern, 1975; McConnell and Servaes, 1990; Hermalin and Weisbach, 1991; и др]. Положительное воздействие высокой концентрации на эффективность деятельности компаний отмечали Мок, Шлейфер и Вишний [Morck, Shleifer and Vishny, 1988], в то время как в других работах [Fama and Jensen, 1983; Grossman and Hart, 1988; Barclay and Holderness, 1989; Burkart et al., 1997; Nenova, 2000; Dyck and Zingales, 2004 и др.], исследовавших конфликты между крупными и мелкими акционерами, возникающие при экспроприации миноритариев мажоритариями, было зафиксировано отрицательное воздействие высокого уровня концентрации собственности. Подтверждение доводу в пользу распыленной собственности можно найти и в работе Зингалес и Райан [Zingales and Rajan, 2003].

В частности, в работе МакИчерна [McEachern, 1975] отмечено, что отсутствие единства мнений в вопросе взаимосвязи между концентрацией собственности и эффективностью деятельности компаний может частично объясняться выделением и анализом лишь нескольких категорий компаний, что, по мнению автора, недостаточно. Несколько позже в своей работе Минтцберг [Mintzberg, 1983] рассмотрел два базовых критерия, используя которые, можно описать большинство компаний. Одними из первых, кто провел детальный анализ компаний с институциональной собственностью и их влиянием на эффективность деятельности компаний, были Чаганти и Даманпур [Chaganti and Damanpour, 1991], до которых фактически ни в одном эмпирическом исследовании не рассматривался вопрос 
дифференциации влияния институциональной собственности, а также возможного взаимодействия институциональных и корпоративных инвесторов при воздействии на поведение компании. Методология этих работ доказала значимость включения в анализ такого аспекта, как идентификация типа собственника. Должное внимание данному вопросу было впервые уделено в работе Томсена и Педерсена [Thomsen and Pedersen, 2000]. Авторы показали, что идентификация типа собственника может оказать значительное содействие при интерпретации разницы в эффективности деятельности компании в зависимости от устоявшейся структуры собственности.

При рассмотрении такого аспекта, как характер зависимости между структурой собственности и эффективностью деятельности компаний, одними из первых, кто обнаружил немонотонную зависимость, были Морк, Шляйфер и Вишны [Morck, Shleifer and Vishny, 1988], причем авторы интерпретировали найденную зависимость доминированием одного из двух эффектов: эффекта конвергенции интересов менеджеров (convergence-of-interest effect) и собственников и эффекта «окапывания» (entrenchment hypothesis). Немонотонный характер зависимости между структурой собственности и эффективностью деятельности компаний был также зафиксирован в работах МакКонелла и Серваэса, Красвелла, Томсена и Педерсена, Уэлч и др.[McConnell and Servaes, 1990; Craswell et al., 1997; Thomsen and Pedersen, 2000; Welch, 2003 ].

Важным аспектом в контексте взаимосвязи структуры собственности и эффективности деятельности компаний является проблема эндогенности структуры собственности. Еще Демсетц и Виллалонга [Demsetz and Villalonga, 2001] отмечали необходимость учета эндогенности структуры собственности, но особое внимание этому вопросу было уделено в работе Уэлч [Welch, 2003], где применялась модель, предложенная Демсетцем и Виллалонгой [Demsetz and Villalonga, 2001], при этом собственность была задана многомерной эндогенно определяемой переменной. Вопрос эндогенности был также затронут в работах Чо, Химмельберга, Холдернесса и пр. [Cho, 1998; Himmelberg et al., 1999; Holderness et al., 1999].

Интерес к вопросу влияния структуры собственности и структуры капитала на эффективность деятельности компании проявили и российские исследователи [Кузнецов и Муравьев, 2000; Guriev et al., 2003; Долгопятова, 2004; Авдашева, Долгопятова, Пляйнес, 2007; Ивашковская и Солнцева, 2009; Степанова, 2009; Ivashkovskaya and Stepanova, 2010; Ивашковская, Кукина, 2009]. Резюмируя основные результаты работ по концентрации собственности в России, стоит отметить следующее: в работе Радыгина и Энтова [2001] было зафиксировано положительное влияние концентрации собственности на эффективность деятельности компании, в то время как Капелюшников и Демина [2005] выявили отрицательную зависимость.

Среди российских работ также стоит отметить исследование Кузнецова и Муравьева [2000], изучающее влияние концентрации собственности на показатели эффективности деятельности компаний и роль различных групп собственников в корпоративном управлении. Авторам удалось прийти к нескольким важным результатам: взаимосвязь между рентабельностью и концентрацией собственности может быть описана U-образной кривой, достигающей минимума при концентрации в 56\%; а также с ростом концентрации собственности рыночная капитализация падает, причем падение происходит с некоторым замедлением. По мнению авторов, полученные результаты следует рассматривать в контексте конфликтов между крупными и мелкими акционерами. Что касается анализа роли различных групп собственников, то эмпирически было доказано, что наличие иностранных акционеров повышает эффективность деятельности компаний, измеряемую производительностью труда и Q Тобина. При этом данный результат был получен с учетом оценки методом инструментальных переменных, без корректировки на эндогенность, и полученный позитивный эффект не был зафиксирован.

В работе Долгопятовой [2004], основанной на интервьюировании руководителей российских ОАО, была предпринята попытка проиллюстрировать связь между структурой 
собственности и корпоративным контролем, с одной стороны, и формами интеграции, с другой. Интервью, проведенные автором, подтверждают, что для российских ОАО характерен высокий уровень концентрации собственности.

Для выдвижения гипотез в данном эмпирическом исследовании были использованы результаты ряда работ [Степанова, 2009; Ivashkovskaya and Stepanova, 2010], в которых анализируюется влияние финансовой архитектуры компании, объединяющей в себе структуру собственности, структуру капитала и корпоративное управление, на стратегическую эффективность. В данных исследованиях была представлена новая переменная, отвечающая за структуру собственности, с целью более полно и достоверно отразить ее влияние на эффективность деятельности компании в разрезе не только развитых европейских, но и развивающихся рынков капитала. В частности, в работе Ивашковской и Степановой [Ivashkovskaya and Stepanova, 2010] было установлено положительное влияние собственности в руках вовлеченных инвесторов на коэффициент Q Тобина, а также эмпирически было доказано, что влияние структуры собственности на эффективность деятельности компании в России и странах Восточной Европы более значимо, чем в развитых странах.

Среди работ по Бразилии хотелось бы отметить исследование Карвалал-да-Сильва [Carvalhal-da-Silva, 2002], в котором рассматривалось влияние концентрации собственности на эффективность деятельности компании, в то время как в работах Карвалал-да-Сильва, Окимура [Carvalhal-da-Silva, 2005; Okimura et al., 2004] исследовался вопрос идентификации типа собственника.

Для проведенного эмпирического исследования наибольший интерес представляли более поздние работы, основанные на бразильских данных. В частности, в работе Алдриджи и Оливейра [Aldrighi and Oliveira, 2007] было проанализировано влияние концентрации собственности в контексте крупнейшего акционера на эффективность деятельности компании, выраженную показателем рентабельности активов. Авторами было проанализировано 600 бразильских компаний за период 1997-2002 годов, и среди основных выводов работы следует отметить тот факт, что концентрация собственности в руках крупнейшего акционера оказывает значительное отрицательное влияние на ROA. Данный результат авторы объясняют экспроприацией мелких акционеров крупными и неэффективностью корпоративного законодательства в Бразилии. Что касается уровня долговой нагрузки, то авторы выявили значимое отрицательное влияние на эффективность деятельности компании, что опровергает концепцию Йенсена [Jensen, 1986] о дисциплинирующем воздействии показателя структуры капитала.

В работе других авторов [Rogers et al., 2007] было проанализировано влияние концентрации собственности на корпоративную эффективность на данных 176 бразильских компаний за 1997-2001 годы и отмечен следующий интересный факт: концентрация собственности поддерживается на высоком уровне при наличии таких механизмов, как пирамидальная структура собственности и выпуск двух видов акций (обыкновенные и привилегированные). В исследовании не было установлено значимой взаимосвязи между показателями концентрации собственности (собственность в руках крупнейшего акционера, собственность в руках трех крупнейших акционеров и индекс Герфиндаля) и эффективностью деятельности компании (Q Тобина и ROE).

\section{Выборка и использованные базы данных}

Выборка проведенного эмпирического исследования состоит из 40 российских и 38 бразильских компаний реального сектора экономики, которые на конец 2008 года котировались на российской площадке РТС и бразильской бирже Bovespa (Bolsa de Valores de São Paulo). B выборку были включены крупнейшие компании стран, большая часть которых входит в национальные фондовые индексы, за исключением компаний финансового сектора. Данные по российским компаниям были взяты из базы Лаборатории корпоративных 
финансов при Государственном университете - Высшей школе Экономики, составленной на основе баз данных Ruslana агентства Van Dijk и Bloomberg, а также отчетов российских компаний. При конструировании выборки по бразильским компаниям за основу был взят отраслевой классификатор Bovespa, данные собирались вручную, анализировалась вся имеющаяся информация на официальных сайтах компаний. Для сбора финансовых показателей была использована база данных Bloomberg.

Таблица 1

Отраслевое распределение компаний выборки

\begin{tabular}{|l|c|c|c|}
\hline \multicolumn{1}{|c|}{ Отрасль } & $\begin{array}{c}\text { Количество } \\
\text { бразильских } \\
\text { компаний }\end{array}$ & $\begin{array}{c}\text { Количество } \\
\text { российских } \\
\text { компаний }\end{array}$ & $\begin{array}{c}\text { Объединенная } \\
\text { выборка }\end{array}$ \\
\hline Нефть и газ & 2 & 3 & 5 \\
\hline Металлургия & 3 & 6 & 9 \\
\hline Строительство & 2 & 0 & 2 \\
\hline Транспорт & 3 & 3 & 6 \\
\hline Промышленность & 6 & 8 & 14 \\
\hline Потребительские товары и ретейл & 5 & 4 & 9 \\
\hline Пищевая промышленность и с/х & 3 & 1 & 4 \\
\hline Телекоммуникации и ИТ & 4 & 4 & 8 \\
\hline Услуги & 3 & 2 & 5 \\
\hline Коммунальные услуги & 7 & 9 & 16 \\
\hline Всего & $\mathbf{3 8}$ & $\mathbf{4 0}$ & $\mathbf{7 8}$ \\
\hline
\end{tabular}

\section{Спецификация модели}

В проведенном эмпирическом исследовании рассматривалась модель влияния структуры собственности на эффективность деятельности компании, которую в общем виде можно специфицировать следующим образом:

Perf $=\alpha+\left(\beta_{1}, \ldots, \beta_{\mathrm{n}}\right) \mathrm{OS}+\left(\delta_{1}, \ldots, \delta_{\mathrm{n}}\right) \mathrm{CG}+\gamma \mathrm{D} / \mathrm{E}+\eta_{1} \ln$ Assets $+\eta_{2} \ln$ Sales $+\left(\lambda_{1}, \ldots\right.$, $\left.\lambda_{\mathrm{n}}\right)$ Dummy $+\varepsilon$,

где Perf - один из показателей эффективности деятельности компаний (Q Тобина; ROA;

Q Tобина с ROA в качестве независимой переменной),

OS - вектор переменных, отвечающих за структуру собственности,

CG - вектор переменных, отвечающих за корпоративное управление,

Dummy - вектор фиктивных переменных, введенных в анализ.

Данная модель была разработана в соответствии с концепцией финансовой архитектуры, основанной на предпосылках об экзогенном характере переменных структуры собственности и структуры капитала. При этом измерение эффективности деятельности компаний было проведено в разрезе трех показателей (Q Тобина; ROA; Q Tобина с ROA в качестве независимой переменной), что позволило нивелировать субъективность выбора в пользу того или иного показателя, а также дало возможность сравнить полученные результаты.

\section{Использованные переменные}

В таблице 2 приведены все независимые переменные, в том числе контрольные и фиктивные. 
Независимые переменные, введенные в анализ

\begin{tabular}{|c|c|}
\hline $\begin{array}{l}\text { Обозначение } \\
\text { переменной }\end{array}$ & Описание \\
\hline 1st major SH \% & Доля акций в руках первого крупнейшего акционера, \% \\
\hline 2nd major SH \% & $\begin{array}{l}\text { Доля акций в руках второго крупнейшего акционера (для России), } \\
\%\end{array}$ \\
\hline BoD Own \% & Доля акций в руках членов совета директоров, \% \\
\hline BoD Size & Количество членов в совете директоров \\
\hline N Bod Ind & Количество независимых членов в совете директоров \\
\hline $\mathbf{D} / \mathbf{E}$ & $\begin{array}{l}\text { Отношение совокупного долга } \\
\text { акционерного капитала компании }\end{array}$ \\
\hline In Assets & Натуральный логарифм совокупных активов \\
\hline In Sales & Натуральный логарифм объемов продаж \\
\hline dummy Country & $\begin{array}{l}\text { Фиктивная переменная, связанная со страновым фактором (для } \\
\text { объединенной выборки) }\end{array}$ \\
\hline du & Фиктивная переменная, связанная с отраслью коммунальных услуг \\
\hline dummy Tele+IT & $\begin{array}{l}\text { Фиктивная переменная, связанная с отраслью телекоммуникаций и } \\
\text { ИТ }\end{array}$ \\
\hline dummy 1st major SH & $\begin{array}{l}\text { Фиктивная переменная, связанная с первым крупнейшим } \\
\text { акционером }\end{array}$ \\
\hline dummy Bol & $\begin{array}{l}\text { Фиктивная переменная, связанная с долей акций в руках членов } \\
\text { совета директоров и исполнительного комитета }\end{array}$ \\
\hline $\begin{array}{l}\text { dummy } \\
\text { Transparency }\end{array}$ & Фиктивная переменная, отвечающая за «открытость» компании \\
\hline dummy N BoD Ind & $\begin{array}{l}\text { Фиктивная переменная, отвечающая за количество независимых } \\
\text { членов совета директоров }\end{array}$ \\
\hline
\end{tabular}

В контексте Бразилии и России структура собственности была рассмотрена с точки зрения концентрации собственности в руках крупнейших акционеров и с позиции инсайдерской собственности, представленной собственностью совета директоров (BoD Own). В ходе сбора данных по бразильским компаниям, а также анализа имеющегося массива данных по России была выявлена следующая статистика относительно раскрытия информации по крупнейшим собственникам, представленная в таблице 3.

Таблица 3

Раскрытие информации о крупнейших собственниках

\begin{tabular}{|l|c|c|c|}
\hline \multicolumn{1}{|c|}{ Известен/ны: } & $\begin{array}{c}\text { Количество } \\
\text { бразильских } \\
\text { компаний }\end{array}$ & $\begin{array}{c}\text { Количество } \\
\text { российских } \\
\text { компаний }\end{array}$ & $\begin{array}{c}\text { Объединенная } \\
\text { выборка }\end{array}$ \\
\hline 1 крупнейший акционер & 38 & 40 & 78 \\
\hline 2 крупнейших акционера & 32 & 40 & 72 \\
\hline 3 крупнейших акционера & 22 & 22 & 44 \\
\hline 4 крупнейших акционера & 10 & 10 & 20 \\
\hline 5 крупнейших акционера & 7 & 10 & 17 \\
\hline
\end{tabular}

Таким образом, в Бразилии и на объединенном массиве была рассмотрена собственность в руках первого крупнейшего акционера $\left(1^{\text {st }}\right.$ major $\left.\mathrm{SH}\right)$, в то время как российские данные позволили включить в анализ также собственность в руках второго 
крупнейшего акционера ( $2^{\text {nd }}$ major $\left.\mathrm{SH}\right)$.

За корпоративный контроль отвечали две переменные: размер совета директоров (BoD Size) и количество независимых членов совета директоров (N BoD Ind).

\section{Тестируемые гипотезы}

Таблица 4

Выдвинутые гипотезы

\begin{tabular}{|l|l|}
\hline $\mathbf{N o}$ & \multicolumn{1}{|c|}{ Формулировка гипотезы } \\
\hline $\mathbf{1}$ & Степень концентрации собственности оказывает значимое влияние на ЭДК \\
\hline $\mathbf{2}$ & Доля акций в руках членов совета директоров отрицательно влияет на ЭДК \\
\hline $\mathbf{3}$ & Уровень долговой нагрузки компании влияет на ЭДК \\
\hline $\mathbf{4}$ & Размер совета директоров влияет на ЭДК \\
\hline $\mathbf{5}$ & Наличие независимых членов совета директоров положительно влияет на ЭДК \\
\hline $\mathbf{6}$ & Уровень долговой нагрузки имеет эндогенный характер \\
\hline $\mathbf{7}$ & Структура собственности имеет эндогенный характер \\
\hline $\mathbf{8}$ & Структура собственности зависит от ЭДК \\
\hline
\end{tabular}

Как отмечено в работе Кузнецова и Муравьева [2000], концентрация акционерного капитала является самым простым способом устранения неэффективности, порождаемой распылением собственности из-за агентских издержек. С другой стороны, высокая концентрация собственности может спровоцировать конфликты между мажоритариями и миноритариями. Таким образом, наиболее корректным было выдвинуть гипотезу № 1 в общем виде: степень концентрации собственности оказывает значимое влияние на эффективность деятельности компаний.

Следующая гипотеза была продиктована желанием проверить, есть ли зависимость между собственностью в руках членов совета директоров и эффективностью деятельности компании. Поскольку фактически этот показатель отражает инсайдерскую собственность, возвращаясь к классическому агентскому конфликту, можно сформулировать гипотезу № 2: большая доля акций в руках членов совета директоров отрицательно влияет на эффективность деятельности компаний.

Учитывая концепции компромиссной теории, а также теории иерархии, гипотезе № 3 имело смысл придать общую формулировку: уровень долговой нагрузки компании влияет на эффективность деятельности компаний.

Принимая во внимание тот факт, что размер совета директоров может оказывать как положительное (теория «зависимости ресурсов»), так и отрицательное влияние на эффективность деятельности компаний (концепция «перенаселения» совета директоров), было целесообразно задать гипотезу № 4 также в обобщенном виде: размер совета директоров оказывает влияние на эффективность деятельности компаний.

Что касается наличия независимых членов в совете директоров, анализ имеющихся работ не позволил сделать однозначного вывода о характере влияния, поэтому авторами была предложена следующая гипотеза: наличие независимых членов совета директоров положительно влияет на эффективность деятельности компаний.

Стоит отметить, что предпосылки об экзогенности переменных, отвечающих за структуру собственности и структуру капитала, введенные при конструировании модели, могут серьезно исказить результаты, если окажутся неверными. Поэтому имеет смысл сформулировать гипотезы № 6 и № 7 об эндогенном характере уровня долговой нагрузки и структуры собственности.

Наконец, было выдвинуто предположение [Кузнецов и Муравьев, 2000; Степанова, 2009] об обратной причинно-следственной связи между структурой собственности и 
эффективностью деятельности компаний. Для выявления данной зависимости была введена гипотеза № 8: структура собственности зависит от эффективности деятельности компаний.

\section{Результаты исследования}

Тестирование представленных выше моделей на описанной выборке позволило авторам получить следующие результаты (см. таблицу 5). Значимость коэффициента Q Тобина на уровне 1,5 и 10\% обозначена соответственно ***, ** и *.

Таблица 5

Результаты тестирования моделей эффективности деятельности компании с коэффициентом QTобина в качестве зависимой переменной

\begin{tabular}{|l|c|c|c|}
\hline & Бразилия & Россия & $\begin{array}{c}\text { Объединенная } \\
\text { выборка }\end{array}$ \\
\hline 1st major SH \% & $-0,004$ & $-1,007^{* *}$ & $-0,006^{* * *}$ \\
\hline 2nd major SH \% & - & $0,937^{*}$ & - \\
\hline BoD Own \% & - & - & - \\
\hline BoD Size & - & - & $-0,037^{*}$ \\
\hline N Bod Ind & - & $0,069^{* *}$ & $0,039^{*}$ \\
\hline D/E & $0,001^{* * *}$ & $-0,189^{*}$ & $0,001^{* *}$ \\
\hline In Assets & - & - & $0,072^{* *}$ \\
\hline In Sales & - & - & $-0,072^{* *}$ \\
\hline ROA & $0,010^{* *}$ & - & $0,015^{* * *}$ \\
\hline dummy BoD Own & $0,334^{* * *}$ & - & - \\
\hline dummy Country & - & - & $-0,531^{* * *}$ \\
\hline $\begin{array}{l}\text { Кол-во } \\
\text { наблюдений }\end{array}$ & 38 & 40 & 78 \\
\hline$R^{2}$ & 0,42 & 0,37 & 0,61 \\
\hline
\end{tabular}

На объединенной выборке по Бразилии и России зафиксирован самый высокий $\mathrm{R}^{2}$. Увеличение объема выборки позволило в данном случае выявить некоторые не столь явные зависимости и, следовательно, уточнить спецификацию модели.

Значимость показателя $1^{\text {st }}$ major $\mathrm{SH} \%$ на уровне $1 \%$ не дает оснований отвергнуть гипотезу № 1 о значимом влиянии концентрации собственности на эффективность деятельности компании. Отрицательное влияние, которое оказывает концентрация собственности на эффективность деятельности компании, было зафиксировано для Бразилии и России, поэтому на межстрановой выборке противоречий не возникло. То же касается и гипотезы № 2 о негативном влиянии собственности в руках членов совета директоров на эффективность, которая отвергается как для Бразилии и России, так и для объединенной выборки. При этом незначимость самого показателя BoD Own\% может быть объяснена подавляющим большинством нулевых значений пакетов акций в руках членов совета директоров как бразильских, так и российских компаний выборки.

Гипотеза № 3 о влиянии структуры капитала на корпоративную эффективность не отвергается для Бразилии, России и межстрановой выборки, однако влияние уровня долга разнонаправленно в двух изучаемых странах. Для российских компаний в период кризиса выявлено значимое отрицательное влияние на коэффициент Q Тобина, что обусловлено превышением уровня заимствования над оптимальным для большинства компаний, что, в свою очередь, обусловило довольно высокий уровень финансовой неустойчивости, особенно выраженный в кризисный год. Для бразильских компаний было выявлено положительное 
влияние уровня долга на эффективность, однако коэффициент при показателе D/E существенно ниже, чем для России, что говорит о меньшей значимости структуры капитала для эффективности бразильских компаний.

Значимость показателя размера совета директоров на 10\%-ном уровне не позволяет отвергнуть на межстрановой выборке гипотезу № 4. «Раздутый» совет директоров усложняет процесс принятия решений и снижает качество корпоративного управления, что соответствует мнению многих топ-менеджеров и финансистов-практиков.

Еще одна характеристика корпоративного управления, тестируемая в работе, - это уровень независимости совета директоров. Межстрановой анализ показал, что число независимых директоров положительно влияет на эффективность российских компаний, в то время как для бразильских компаний оно незначимо. Высокий уровень значимости независимых директоров в российской бизнес-среде был продемонстрирован также и на докризисных данных в работе Ивашковской и Степановой [Ivashkovskaya, Stepanova, 2010].

Будучи важным аспектом в контексте эффективности деятельности компаний, проблема эндогенности структуры собственности и структуры капитала была рассмотрена в зарубежных и российских исследованиях [Cho, 1998; Holderness et al., 1999; Himmelberg et al., 1999; Demsetz and Villalonga, 2001; Brailsford et al., 2002; Welch, 2003; Aldrighi and Olivera, 2007; Кузнецов и Муравьев, 2000; Степанова, 2009; Ivashkovskaya and Stepanova, 2010]. Для полноценного изучения проблемы эндогенности в данном исследовании необходимо существенное расширение выборки, однако авторами были проведены пилотные тесты на эндогенность структуры собственности и структуры капитала, а также проверка обратной причинно-следственной связи. Авторы построили ряд регрессий, которые показали, что уровень долговой нагрузки и структура собственности на межстрановой выборке зависят от таких индивидуальных характеристик компании, как еe размер (ln Assets, In Sales), рентабельность активов (ROA), а также коэффициент Тобина (Q Tobin). Таким образом, оснований отвергать гипотезы № 6--8 об эндогенном характере структуры капитала и структуры собственности и наличии обратной причинно-следственной связи нет. Однако изучение эндогенности компонентов финансовой архитектуры представляет собой обширное поле для дальнейших исследований, а тестирование гипотез о наличии обратной причинноследственной связи требует проведения исследований с помощью панельных данных.

\section{Заключение}

Авторами разработана и верифицирована на данных бразильских и российских компаний модель влияния структуры собственности и других компонентов финансовой архитектуры на эффективность деятельности компании, а также выявлены страновые особенности спецификации модели для России и Бразилии, одних из наиболее быстро развивающихся стран в мире.

Среди основных выводов работы можно отметить, во-первых, эмпирическое доказательство того, что концентрация собственности, измеренная показателем акций в руках крупнейшего акционера, оказывает значительное отрицательное влияние на эффективность деятельности компаний.

Данный результат справедлив в отношении России, Бразилии и объединенной выборки. Более того, он находит подтверждение в работах российских авторов [Кузнецов и Муравьев, 2000] и исследованиях по Бразилии [Rogers et al., 2007; Aldrighi and Olivera, 2007], а также соотносится с концепцией, выдвинутой в других работах [Barclay and Holderness, 1989; Burkart et al., 1997; Nenova, 2000; Dyck and Zingales, 2004; и др.] и объясняющей отрицательное воздействие концентрации собственности через призму конфликтов между мажоритариями и миноритариями.

Во-вторых, стоит отметить сохранившуюся тенденцию в отношении высокой концентрации собственности, характерную для бразильских и российских компаний. Следует также обратить внимание на то, что в среднем по бразильской выборке в руках 
первого крупнейшего акционера сосредоточено 47,6\% собственности в 2008 году, что практически идентично значению, отмеченному в работе Алдриджи и Оливейра [Aldrighi and Olivera, 2007], где средняя концентрация собственности бразильских компаний за 1997-2002 годы, измеренная по показателю первого крупнейшего собственника, составляла 46,4\%. В руках первого крупнейшего акционера в России в 2008 году сосредоточено в среднем 42,3\% собственности, что в целом идентично показателю в $40 \%$ для российских компаний начала 2000-х [Капелюшников, 2001; Долгопятова, 2004]. Проведенное исследование зафиксировало отрицательное влияние высокой концентрации для бразильских и российских компаний, что противоречит работе Морка, Шляйфера и Вишны [Morck, Shleifer and Vishny, 1988], которые указывали на содействие крупного акционера развитию рынка корпоративного контроля и улучшение результатов деятельности фирм.

В-третьих, на объединенной выборке была выявлена значимость странового фактора, отмеченные страновые различия касаются показателя независимых членов совета директоров, уровня долговой нагрузки и ROA в качестве независимой переменной. Устойчивость положительного коэффициента при показателе независимых членов совета директоров свидетельствует о позитивном воздействии на стратегическую эффективность, при этом различная значимость данного показателя может объясняться соответствующим уровнем развития института независимого директора в России и Бразилии. Также для российских компаний зафиксирована отрицательная корреляция между D/E и Q Тобина, что согласуется с теорией иерархии и может объясняться превышением оптимального уровня D/E [Степанова, 2009; Ivashkovskaya and Stepanova, 2010], чего нельзя сказать о Бразилии. Для российских компаний нехарактерно включение ROA в качестве независимой переменной, в то время как для бразильских компаний показатель прибыльности оказался весьма значимым.

Модели, представленные в работе, доказали устойчивость коэффициентов и показали высокую объясняющую силу, поэтому могут быть рекомендованы для использования на практике при решении задачи повышения показателя стратегической эффективности компании (в управлении капиталом и в деятельности советов директоров как российских, так и бразильских компаний, а также в сфере консалтинга). В качестве перспектив для дальнейшего развития заданного в работе направления можно выделить включение в анализ временных данных для сопоставления результатов в динамике, расширение количества наблюдений, а также рассмотрение вопроса идентификации типа собственника, что позволит задействовать новый пласт данных и потенциально позволит ввести институциональный фактор в анализ.

\section{Список литературы}

1. Авдашева С., Долгопятова Т., Пляйнес X. Корпоративное управление в АO с государственным участием: российские проблемы в контексте мирового опыта. М.: ГУ-ВШЭ, 2007.

2. Долгопятова Т. Собственность и корпоративный контроль в российских компаниях в условиях активизации интеграционных процессов // Русский журнал менеджмента. 2004. № 2. С. 3-26.

3. Ивашковская И., Кукина Е. Детерминанты экономической прибыли крупных российских компаний // Электронный журнал «Корпоративные финансы». - 2009. №4 (12).

4. Ивашковская И., Солнцева М. Детерминанты стратегических решений о финансировании крупных компаний на развивающихся рынках капитала: пример России, Бразилии и Китая // Российский журнал менеджмента. 2009. Т. 7. С. 25-42.

5. Капелюшников Р., Демина Н. Концентрация собственности и поведение российских промышленных предприятий // Вестник общественного мнения. 2005. № 3(77).

6. Кузнецов П., Муравьев А. Структура акционерного капитала и результаты 
деятельности в России // Экономический журнал ВШЭ. 2000. №4. С. 475- 504.

7. Радыгин А., Энтов Р. Корпоративное управление и защита прав собственности: эмпирический анализ и актуальное направление реформ // Научные труды ИЭПП № 36. 2001. С. 26-45.

8. Степанова А. Влияние финансовой архитектуры компании на ее стратегическую эффективность // Финансы и кредит. 2009. С. 38-45.

9. Aldrighi, M., Oliveira, A. (2007), The Influence of Ownership and Control Structures on the Firm Performance: Evidence from Brazil. SSRN Working Paper, p. 1-18.

10. Barclay, M., Holderness, C. (1989), Private Benefits from Control of Public Corporations, Journal of Financial Economics, 25 (1989) 371-395.

11. Brailsford, T., Oliver, P., Pua, S. (2002), On the Relation of Ownership Structure and Capital Structure, Accounting and Finance, 42 (2002) 1-26.

12. Burkart, M., Gromb, D., Panunzi, F. (1997), Large Shareholders, Monitoring and the Value of the Firm, Quarterly Journal of Economics, 112(3) (1997) 693-728.

13. Carvalhal-Da-Silva, A. (2002), Corporate Governance Index, Firm Valuation and Performance in Brazil, Rio de Janeiro: E-Papers.

14. Carvalhal-Da-Silva, A. (2005), Corporate Governance, Market Valuation and Dividend Policy in Brazil, RAUSP, San-Paulo, 39(4) (2005) 348-361.

15. Chaganti R., Damanpour, F. (1991), Institutional ownership, capital structure and firm performance, Strategic Management Journal, 12 (1991) 479-491.

16. Cho, M. (1998), Ownership Structure, Investment and the Corporate Value: An Empirical Analysis, Journal of Financial Economics, 47 (1998) 103-121.

17. Craswell A., Taylor S., Saywell, R. (1997), Ownership Structure and Corporate Performance: Australian Evidence, Pacific-Basin Finance Journal, 5 (1997) 301-323.

18. Demsetz H., Villalonga. B. (2001), Ownership Structure and Corporate Performance, Journal of Corporate Finance, 7 (2001) 209-233.

19. Dyck, A., Zingales, L. (2004), Private Benefits of Control: An International Comparison, Journal of Finance, 59 (2004) 537- 601.

20. Guriev, S., Lazareva, O., Rachinski, A., Tsouhlo, S. (2003), Concentrated Ownership, Market for Corporate Control and Corporate Governance, CEFIR Project (2003) 1-23.

21. Himmelberg, C., Hubbard, G., Palia, D. (1999), Understanding the Determinants of Managerial Ownership and Performance, Journal of Financial Economics, 5 (1999) 353384.

22. Holderness, C., Kroszner, R., Sheehan, D. (1999), Were the Good Old Days That Good? Changes in Managerial Stock Ownership since the Great Depression, Journal of Finance, 54 (2) (1999) 435-469.

23. Ivashkovskaya, I., Stepanova, A. (2010), Does Strategic Corporate Performance Depend on Corporate Financial Architecture? Empirical Study of European, Russian and Other Emerging Market's Firms, Journal of Management and Governance, (2010) 1-14.

24. Jensen, M. (1986), Agency Costs of Free Cash Flow, Corporate Finance, and Takeovers, American Economic Review, 76 (1986) 323-339.

25. McConnell, J., Servaes, H. (1990), Additional Evidence on Equity Ownership and Corporate Value, Journal of Financial Economics, 27 (1990) 597-612.

26. McEachern, W. (1975), Managerial Control and Performance. Lexington Books.

27. Mintzberg, H. (1983), Power in and Around Organizations. Prentice-Hall, EngleWood Cliffs, NJ.

28. Monsen, R., Chiu, J., Cooley, D. (1968), The Effect of Separation of Ownership and Control on the Performance of the Large Firm, Quarterly Journal of Economics, 82(3) (1968) 435451 .

29. Morck, R., Shleifer, A., Vishny, R. (1988), Management Ownership and Market Valuation: an Empirical Analysis, Journal of Finance Economics, 20 (1988) 293-315.

30. Myers, S. (1999), Financial Architecture, European Financial Management, 5 (1999) 113- 
141.

31. Nenova, T. (2000), The Value of Corporate Votes and Control Benefits: A Cross Country Analysis, Harvard University Working Paper.

32. Okimura, R., Silveira, A., Rocha, K. (2004), Estrutura de propriedade e desempenho corporativo no Brasil, ANPAD Working Paper.

33. Rogers, P., Dami, A., Ribeiro, K., Sousa, A. (2007), Corporate Governance and Ownership Structure in Brazil: Causes and Consequences, SSRN Working Paper, 1-26.

34. Thomsen, S., Pedersen, T. (2000), Ownership Structure and Economic Performance in the Largest European Companies, Strategic Management Journal, 21 (6) (2000) 689-705.

35. Welch E. (2003), The Relationship between Ownership Structure and Performance in Listed Australian Companies, Australian journal of management, 28 (3) (2003) 287-306.

36. Zingales, L., Rajan, R. (2003), Saving Capitalism from the Capitalists: Unleashing the Power of Financial Markets to Create Wealth and Spread Opportunity. New York, Crown Business. 